\title{
Critical care management of severe traumatic brain injury in adults
}

Samir $\mathrm{H} \mathrm{Haddad}^{1 *}$ and Yaseen $\mathrm{M} \mathrm{Arabi}^{2}$

\begin{abstract}
Traumatic brain injury (TBI) is a major medical and socio-economic problem, and is the leading cause of death in children and young adults. The critical care management of severe TBI is largely derived from the "Guidelines for the Management of Severe Traumatic Brain Injury" that have been published by the Brain Trauma Foundation. The main objectives are prevention and treatment of intracranial hypertension and secondary brain insults, preservation of cerebral perfusion pressure (CPP), and optimization of cerebral oxygenation. In this review, the critical care management of severe TBI will be discussed with focus on monitoring, avoidance and minimization of secondary brain insults, and optimization of cerebral oxygenation and CPP.
\end{abstract}

Keywords: Traumatic brain injury, head injury, head trauma, critical care

\section{Introduction}

Severe traumatic brain injury (TBI), defined as head trauma associated with a Glasgow Coma Scale (GCS) score of 3 to 8 [1], is a major and challenging problem in critical care medicine. Over the past twenty years, much has been learned with a remarkable progress in the critical care management of severe TBI. In 1996, the Brain Trauma Foundation (BTF) published the first guidelines on the management of severe TBI [2] that was accepted by the American Association of Neurological Surgeons and endorsed by the World Health Organization Committee in Neurotraumatology. The second revised edition was published in 2000 [3] with an update in 2003, and the $3^{\text {rd }}$ edition was published in 2007 [4]. Several studies have reported the impact of implementation of guidelines-based management protocols for severe TBI on patient's treatment and outcome $[5,6]$. These studies have clearly demonstrated that the implementation of protocols for the management of severe TBI, incorporating recommendations from the guidelines, is associated with substantially better outcomes such as mortality rate, functional outcome scores, length of hospital stay, and costs $[7,8]$. However, there is still

\footnotetext{
* Correspondence: haddads55@yahoo.com

'Surgical Intensive Care Unit, Intensive Care Department, King Abdulaziz Medical City, PO Box 22490, Riyadh 11426, K.S.A

Full list of author information is available at the end of the article
}

considerable and wide institutional variation in the care of patients with severe TBI.

In general, TBI is divided into two discrete periods: primary and secondary brain injury. The primary brain injury is the physical damage to parenchyma (tissue, vessels) that occurs during traumatic event, resulting in shearing and compression of the surrounding brain tissue. The secondary brain injury is the result of a complex process, following and complicating the primary brain injury in the ensuing hours and days. Numerous secondary brain insults, both intracranial and extracranial or systemic, may complicate the primarily injured brain and result in secondary brain injury. Secondary, intracranial brain insults include cerebral edema, hematomas, hydrocephalus, intracranial hypertension, vasospasm, metabolic derangement, excitotoxicity, calcium ions toxicity, infection, and seizures $[9,10]$. Secondary, systemic brain insults are mainly ischemic in nature $[9,11]$, such as:

- Hypotension (systolic blood pressure [SBP] $<90$ $\mathrm{mm} \mathrm{Hg}$ )

- Hypoxemia $\left(\mathrm{PaO}_{2}<60 \mathrm{~mm} \mathrm{Hg} ; \mathrm{O}_{2}\right.$ Saturation < 90\%)

- Hypocapnia $\left(\mathrm{PaCO}_{2}<35 \mathrm{~mm} \mathrm{Hg}\right)$

- Hypercapnia $\left(\mathrm{PaCO}_{2}>45 \mathrm{~mm} \mathrm{Hg}\right)$

- Hypertension (SBP > $160 \mathrm{~mm} \mathrm{Hg}$, or mean arterial pressure $[\mathrm{MAP}]>110 \mathrm{~mm} \mathrm{Hg}$ )

\section{Biomed Central}


- Anemia (Hemoglobin $[\mathrm{Hb}]<100 \mathrm{~g} / \mathrm{L}$, or hematocrit $[\mathrm{Ht}]<0.30)$

- Hyponatremia (serum sodium $<142 \mathrm{mEq} / \mathrm{L}$ )

- Hyperglycemia (blood sugar $>10 \mathrm{mmol} / \mathrm{L}$ )

- Hypoglycemia (blood sugar $<4.6 \mathrm{mmol} / \mathrm{L}$ )

- Hypo-osmolality (plasma osmolality [P Osm] $<290$ $\mathrm{mOsm} / \mathrm{Kg} \mathrm{H}_{2} \mathrm{O}$ )

- Acid-base disorders (acidemia: $\mathrm{pH}<7.35$; alkalemia: $\mathrm{pH}>7.45)$

- Fever (temperature $>36.5^{\circ} \mathrm{C}$ )

- Hypothermia (temperature $<35.5^{\circ} \mathrm{C}$ )

Hence, it is now clear that only part of the damage to the brain during head trauma is from the primary brain injury, which is not amenable to alteration and cannot be reversed. However, secondary brain insults are often amenable to prevention or reversal.

The intensive care management of patients with severe TBI is a dynamic process, starts in the pre-hospital period, at the scene of the accident. During the early stages of hospital care, the patients may be managed in a variety of locations including emergency department, the radiology department, and the operating room before they are admitted to the Intensive Care Unit (ICU). The continuum of acute care, during the "GOLDEN HOUR", from the time of injury through the start of definitive care, should be ensured and based on the guidelines and recommendations previously mentioned. This review outlines the fundamental principles of critical care management of patients with severe TBI during their stay in the ICU. See Figure 1

\section{Critical care management of severe TBI}

Prior to arrival to the ICU, patients with severe TBI are usually received, resuscitated and stabilized in emergency department or operating room. Once the severely head-injured patient has been transferred to the ICU, the management consists of the provision of high quality general care and various strategies aimed at maintaining hemostasis with:

- Stabilization of the patient, if still unstable

- Prevention of intracranial hypertension

- Maintenance of an adequate and stable cerebral perfusion pressure (CPP)

- Avoidance of systemic, secondary brain insults (SBI)

- Optimization of cerebral hemodynamic and oxygenation

\section{Monitoring}

Monitoring of patients with severe TBI is essential for the guidance and optimization of therapy. The rationale of monitoring is early detection and diagnosis of secondary brain insults, both systemic and intracranial. Therefore, monitoring of patients with severe TBI must comprise both general and specific neurologic monitoring.

\section{General monitoring}

During neurointensive care of patients with severe TBI, general parameters that are regularly monitored include electrocardiography (ECG monitoring), arterial oxygen saturation (pulse oxymetry, $\mathrm{SpO}_{2}$ ), capnography (endtidal $\mathrm{CO}_{2}$, PetCO $\mathrm{C}_{2}$ ), arterial blood pressure (arterial catheter), central venous pressure (CVP), systemic temperature, urine output, arterial blood gases, and serum electrolytes and osmolality. Invasive or non-invasive cardiac output monitoring may be required in hemodynamically unstable patients who do not respond to fluid resuscitation and vasopressors.

\section{Neuromonitoring \\ Intracranial pressure monitoring}

The BTF recommends that "intracranial pressure (ICP) should be monitored in all salvageable patients with a severe TBI and an abnormal computed tomography (CT) scan". Also, "ICP monitoring is indicated in patients with severe TBI with a normal CT scan if two or more of the following features are noted at admission: age over 40 years, unilateral or bilateral motor posturing, or systolic blood pressure (BP) $<90 \mathrm{~mm} \mathrm{Hg"} \mathrm{[4].}$ Based on physiological principles, potential benefits of ICP monitoring include earlier detection of intracranial mass lesion, guidance of therapy and avoidance of indiscriminate use of therapies to control ICP, drainage of cerebrospinal fluid (CSF) with reduction of ICP and improvement of CPP, and determination of prognosis.

Currently, available methods for ICP monitoring include epidural, subdural, subarachnoid, parenchymal, and ventricular locations. Historically, ventricular ICP catheter has been used as the reference standard and the preferred technique when possible. It is the most accurate, low-cost, and reliable method of monitoring ICP [4]. It also allows for continuous measurement of ICP and for therapeutic CSF drainage in the event of intracranial hypertension to control raised ICP. Subarachnoid, subdural, and epidural monitors are less accurate. ICP monitor is usually placed via the right side, since in approximately $80 \%$ of the populations the right hemisphere is the non-dominant, unless contraindicated [12]. However, it might be placed on the side with maximal pathological features or swelling [13]. Routine ventricular catheter change or prophylactic antibiotic use for ventricular catheter placement is not recommended to reduce infection [4]. However, ICP monitoring devices are usually continued for $\leq 1$ week; with daily 


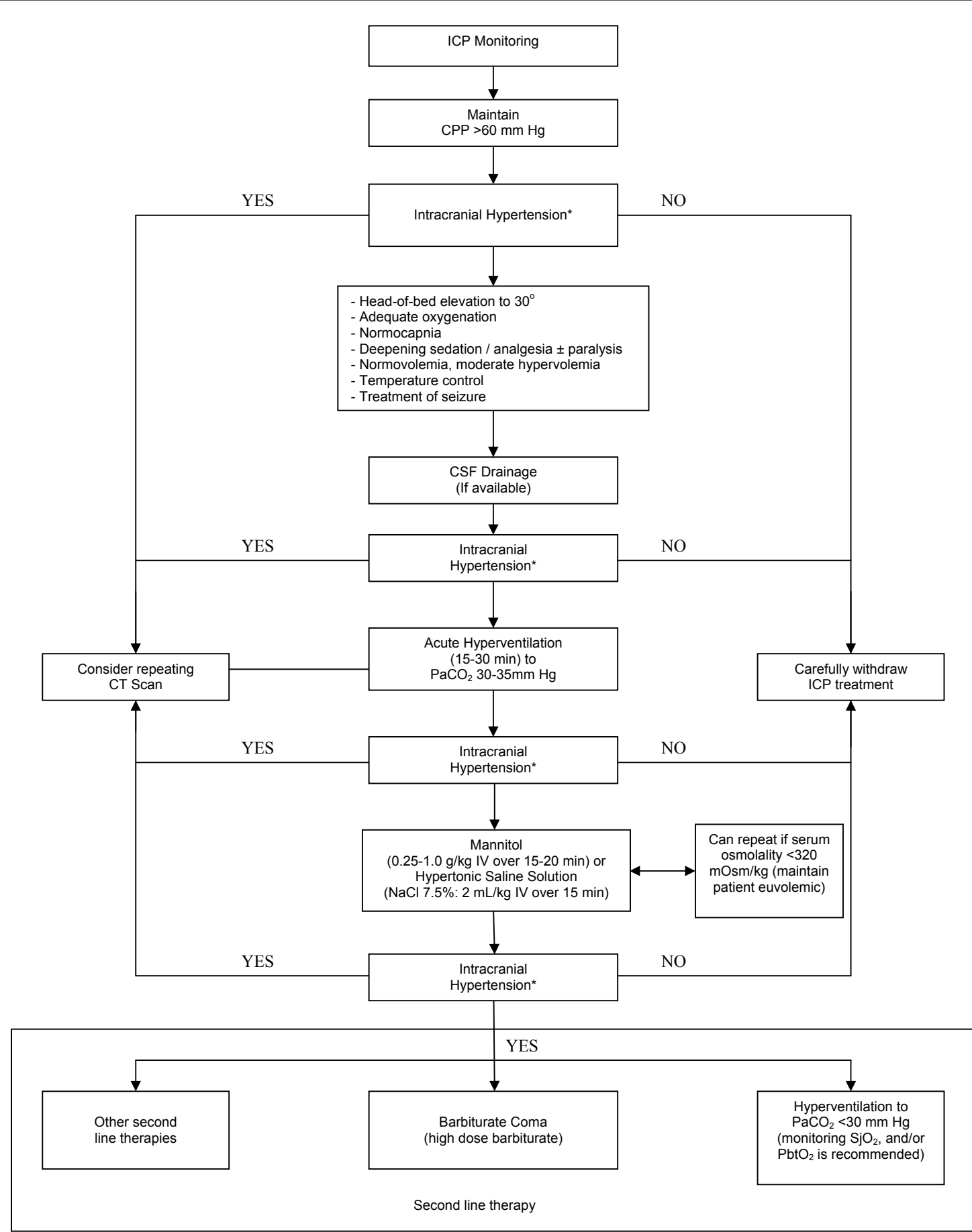

* ICP of $20-25 \mathrm{~mm} \mathrm{Hg}$ is used as the treatment threshold.

Figure 1

examination of the CSF for glucose, protein, cell count, Gram stain, and culture and sensitivity. Treatment for intracranial hypertension should be started with ICP thresholds above $20 \mathrm{~mm} \mathrm{Hg}$. Additional to ICP values, clinical and brain CT findings should be used to determine the need for treatment [4].

Although there is no randomized, controlled trial (RCT) that has been performed demonstrating that ICP 
monitoring improves outcome or supporting its use as standard; ICP monitoring has become an integral part in the management of patients with severe TBI in most trauma centers. However, there is contradicting evidence about whether ICP monitoring improves outcome. Several studies have demonstrated that ICP monitoring reduced the overall mortality rate of severe TBI [14-21]. Other studies have not shown benefits from ICP monitoring [22-24]. Moreover, a few studies have demonstrated that ICP monitoring was associated with worsening of survival $[25,26]$. Potential complications of ICP monitoring include infection, hemorrhage, malfunction, obstruction, or malposition. Recently, we reported that in patients with severe TBI, ICP monitoring was not associated with reduced hospital mortality, however, with a significant increase in mechanical ventilation duration, need for tracheotomy, and ICU length of stay [27]. In the Cochrane database, a recent systematic review found no RCTs that can clarify the role of ICP monitoring in acute coma whether traumatic or nontraumatic [26]. Nevertheless, there is evidence, and most clinicians agree, to support the use of ICP monitoring in severe TBI patients at risk for intracranial hypertension. Absolute ICP values are independent predictors of neurologic outcomes; however, refractory ICP and response to treatment of raised ICP could be better predictors of neurological outcome than absolute ICP values [28]. Treggiari et al. conducted a systematic review to estimate the association between ICP values and patterns and short- and long-term vital and neurological outcome. Relative to normal ICP $(<20 \mathrm{~mm} \mathrm{Hg})$, raised ICP was associated with elevated odds ratio (OR) of death: 3.5 [95\%CI: 1.7, 7.3] for ICP 20-40, and 6.9 [95\% CI: 3.9, 12.4] for ICP $>40 \mathrm{~mm} \mathrm{Hg}$. Raised but reducible ICP was associated with a 3-4-fold increase in the ORs of death or poor neurological outcome. Refractory ICP pattern was associated with a dramatic increase in the relative risk of death (OR $=114.3$ [95\%CI: 40.5, 322.3]) [29].

\section{Jugular bulb venous oxygen saturation}

The jugular venous oxygen saturation $\left(\mathrm{SjvO}_{2}\right)$ is an indicator of both cerebral oxygenation and cerebral metabolism, reflecting the ratio between cerebral blood flow $(\mathrm{CBF})$ and cerebral metabolic rate of oxygen $\left(\mathrm{CMRO}_{2}\right)$. A retrograde catheterization of the internal jugular vein (IJV) is used for $\mathrm{SjvO}_{2}$ monitoring. As the right IJV is usually dominant [30], it is commonly used for cannulation to reflect the global cerebral oxygenation [31]. Monitoring $\mathrm{SjvO}_{2}$ can be either continuous via a fiberoptic catheter or intermittent via repeated blood samples. In a prospective study of patients with severe acute brain trauma and intracranial hypertension, Cruz concluded that continuous monitoring of $\mathrm{SjvO} 2$ was associated with improved outcome [32]. The normal average of the $\mathrm{SjVO}_{2}$, in a normal awake subject, is $62 \%$ with a range of $55 \%$ to $71 \%$. A sustained jugular venous desaturation of $<50 \%$ is the threshold of cerebral ischemia and for treatment [33]. $\mathrm{SjVO}_{2}$ monitoring can detect clinically occult episodes of cerebral ischemia, allowing the prevention of these episodes by simple adjustment of treatment. In TBI, jugular venous desaturation is mostly related to CBF reduction secondary to decreased CPP (hypotension, intracranial hypertension, and vasospasm) or hypocapnia-associated cerebral vasoconstriction. Studies showed that a sustained reduction of the $\mathrm{SjvO} 2<50 \%$ was associated with poor outcome, and an independent risk factor for poor prognosis [34-37]. Consequently, $\mathrm{SjvO}_{2}$ monitoring is essential for adjustment of ventilation during the medical treatment of an established intracranial hypertension. However, the benefit of $\mathrm{SjvO}_{2}$ monitoring on severe TBI patients' outcomes has not been confirmed in a RCT.

\section{Brain tissue oxygen tension}

Both $\mathrm{SjvO}_{2}$ and brain tissue oxygen tension $\left(\mathrm{PbtO}_{2}\right)$ monitoring measure cerebral oxygenation, however, $\mathrm{SjvO}_{2}$ measures global cerebral oxygenation and $\mathrm{PbtO}_{2}$ measures focal cerebral oxygenation using an invasive probe (Licox). Rosenthal et al. documented that, measurements of $\mathrm{PbtO}_{2}$ represent the product of $\mathrm{CBF}$ and the cerebral arteriovenous oxygen tension difference rather than a direct measurement of total oxygen delivery or cerebral oxygen [38]. As $\mathrm{PbtO}_{2}$ provides a highly focal measurement, it is mainly used to monitor oxygenation of a critically perfused brain tissue. $\mathrm{PbtO}_{2}$ is the most reliable technique to monitor focal cerebral oxygenation in order to prevent episodes of desatuartion. However, global cerebral oxygenation alterations may not be observed. The normal $\mathrm{PbtO}_{2}$ ranges between 35 $\mathrm{mm} \mathrm{Hg}$ and $50 \mathrm{~mm} \mathrm{Hg}$ [39]. A value of a $\mathrm{PbtO}_{2}<15$ $\mathrm{mm} \mathrm{Hg}$ is considered a threshold for focal cerebral ischemia and treatment [4]. Several studies demonstrated that $\mathrm{PbtO}_{2}$-based therapy may be associated with reduced patient mortality and improved patient outcome after severe TBI [40-42]. In a recent systematic review, available medical literature was reviewed to examine whether $\mathrm{PbtO}_{2}$-based therapy is associated with improved patient outcome after severe TBI [43]. Among patients who received $\mathrm{PbtO}_{2}$-based therapy, 38.8\% had unfavorable and $61.2 \%$ had a favorable outcome. Among the patients who received ICP/CPP-based therapy $58.1 \%$ had unfavorable and $41.9 \%$ had a favorable outcome. Overall $\mathrm{PbtO}_{2}$-based therapy was associated with favorable outcome $(\mathrm{OR}=2.1 ; 95 \% \mathrm{CI}=1.4-3.1)$. These results suggested that combined ICP/CPP- and $\mathrm{PbtO}_{2-}$ based therapy is associated with better outcome after severe TBI than ICP/CPP-based therapy alone [43]. Oddo et al. reported that brain hypoxia or reduced $\mathrm{PbtO}_{2}$ is an independent outcome predictor and is associated with poor short-term outcome after severe TBI 
independently of elevated ICP, low CPP, and injury severity. $\mathrm{PbtO}_{2}$ may be an important therapeutic target after severe TBI [44]. $\mathrm{PbtO}_{2}$ has been documented to be superior to $\mathrm{SjVO}_{2}$, near infrared spectroscopy [45], and regional transcranial oxygen saturation [46] in detecting cerebral ischemia. $\mathrm{PbtO}_{2}$ monitoring is a promising, safe and clinically applicable method in severe TBI patients; however, it is neither widely used nor available. The combinations of ICP/PbtO2 intra-parenchymal monitoring are important and helpful modalities in the management of severe TBI.

\section{Cerebral microdialysis}

Cerebral microdialysis (MD) is a recently developed invasive laboratory device, bedside monitor to analyze brain tissue biochemistry [47]. Usually, a MD catheter is inserted in "susceptible" brain tissue to measure biochemical changes in the area of brain most vulnerable to secondary insults. Different assays are available to measure dialysate concentrations including glucose, lactate, pyruvate, glycerol, and glutamate.

Characteristically, cerebral hypoxia or ischemia results in a significant increase in the lactate: pyruvate ratio (LPR) [48]. A LPR > 20-25 is considered a threshold for cerebral ischemia and is associated with poor outcome in TBI [49]. Although, MD is a well-established tool that provides additional assistance in the management of patients with severe TBI, its use is very limited.

\section{Transcranial Doppler Ultrasonography}

Transcranial Doppler (TCD) is a non-invasive method to measure $\mathrm{CBF}$ velocity. It is increasingly utilized in neurocritical care including TBI. It is a clinically useful tool in the diagnosis of complications that may occur in patients with TBI such as vasospasm, critical elevations of ICP and decreases in CPP, carotid dissection, and cerebral circulatory arrest (brain death). TCD can predict post-traumatic vasospasm prior to its clinical manifestations. Since ICP monitoring is an invasive procedure with potential risk of associated complications, TCD has been suggested as a non-invasive alternative technique for assessment of ICP and CPP [50,51]. The overall sensitivity of TCD for confirming brain death is $75 \%$ to $88 \%$, and the overall specificity is $98 \%$ $[52,53]$. Although, TCD is an established monitoring modality in neurocritical care, evidence to support its regular use for ICP/CPP management in severe TBI patients is lacking.

\section{Electrophysiological monitoring}

Electroencephalogram (EEG) is a clinically useful tool for monitoring the depth of coma, detecting non-convulsive (sub-clinical) seizures or seizures activity in pharmacologically paralyzed patients, and diagnosing brain death $[54,55]$. Continuous EEG has been suggested for the diagnosis of post-traumatic seizures (PTS) in patients with TBI, especially in those who are receiving neuromuscular blockades.

Sensory-evoked potentials (SEP) can yield data on current brain function in very severe TBI patients; however, their use is very limited in the initial management of TBI.

\section{Near infrared spectroscopy}

Near infrared spectroscopy (NIRS) is a continuous, direct, and non-invasive monitor of cerebral oxygenation and cerebral blood volume (CBV). In cerebral tissue, the two main chromophores (light-absorbing compounds) are hemoglobin $(\mathrm{Hb})$ and cytochrome oxidase. NIRS is based on the differential absorption properties of these chromophores in the NIR range, i.e., between 700 and $1,000 \mathrm{~nm}$. At $760 \mathrm{~nm}, \mathrm{Hb}$ occurs primarily in the deoxygenated state (deoxyHb), whereas at $850 \mathrm{~nm}$, it occurs in the oxygenated state (oxyHb). Hence, by monitoring the difference in absorbency between these two wavelengths, the degree of tissue deoxygenation can be evaluated.

In comparison with the $\mathrm{SjvO}_{2}$, NIRS is less accurate in determining cerebral oxygenation [56]. Although, NIRS is an evolving technology and a potential as a clinical tool for bedside cerebral oxygenation and CBF measurements, its use in neurocritical care remains very limited.

\section{Brain temperature}

After head trauma, a temperature gradient in brain temperature compared with body temperature of up to $3^{\circ} \mathrm{C}$ higher in the brain has been reported. Elevated temperature is a common secondary systemic insult to the injured brain. Both invasive (The new Licox PMO: Integra LifeSciences, Plainsboro, NJ) [57] and non-invasive [58], continuous cerebral temperature monitoring devices are commercially available for measuring the brain temperature. However, brain temperature monitoring is still not widely used during neurocritical care of patients with severe TBI.

\section{Critical Care Management}

Guidelines for the management of severe TBI are widely available and should constitute the main background and cornerstone for the development of institutional clinical practice guidelines-based management protocols. Several studies have demonstrated the importance and the impact of implementation of such protocols on the outcomes of patients with severe TBI [5-7]. We reported that the utilization of a clinical practice guidelines-based protocol for severe TBI was associated with a significant reduction in both ICU and hospital mortalities [8].

\section{Analgesia, sedation and paralysis}

In severe TBI patients, endotracheal intubation, mechanical ventilation, trauma, surgical interventions (if any), nursing care and ICU procedures are potential 
causes of pain. Narcotics, such as morphine, fentanyl and remifentanil, should be considered first line therapy since they provide analgesia, mild sedation and depression of airway reflexes (cough) which all required in intubated and mechanically ventilated patients. Administration of narcotics is either as continuous infusions or as intermittent boluses.

Adequate sedation potentiates analgesics; provides anxiolysis; limits elevations of ICP related to agitation, discomfort, cough or pain; facilitates nursing care and mechanical ventilation; decrease $\mathrm{O}_{2}$ consumption, $\mathrm{CMRO}_{2}$, and $\mathrm{CO}_{2}$ production; improves patient comfort; and prevents harmful movements. The ideal sedative for TBI patient would be rapid in onset and offset, easily titrated to effect, and lack active metabolites. It would be anticonvulsant, able to lower ICP and $\mathrm{CMRO}_{2}$, and to preserve the neurologic examination. Finally, it would lack deleterious cardiovascular effects. No commonly used sedative is ideal. Propofol is the hypnotic of choice in patients with an acute neurologic insult, as it is easily titratable and rapidly reversible once discontinued. These properties permit predictable sedation yet allow for periodic neurologic evaluation of the patient. However, propofol should be avoided in hypotensive or hypovolemic patients because of its deleterious hemodynamic effects. Moreover, propofol infusion syndrome (rhabdomyolysis, metabolic acidosis, renal failure, and bradycardia) is a potential complication of prolonged infusions or high doses of propofol administration. Benzodiazepines such as midazolam and lorazepam are recommended as continuous infusion or intermittent boluses. In addition to sedation, they provide amnesia and anticonvulsive effect. Prolonged infusion, high dose, presence of renal or hepatic failure, and old age are risk factors for accumulation and oversedation.

Routine use of neuromuscular blocking agents (NMBAs) to paralyze patients with TBI is not recommended. NMBAs reduce elevated ICP and should be considered as second line therapy for refractory intracranial hypertension. However, the use of a NMBA is associated with increased risk of pneumonia and ICU length of stay (LOS), and with neuromuscular complications.

\section{Mechanical ventilation}

Patients with severe TBI are usually intubated and mechanically ventilated. Hypoxia, defined as $\mathrm{O}_{2}$ saturation $<90 \%$, or $\mathrm{PaO}_{2}<60 \mathrm{~mm} \mathrm{Hg}$, should be avoided [4]. Prophylactic hyperventilation to a $\mathrm{PaCO}_{2}<25 \mathrm{~mm}$ $\mathrm{Hg}$ is not recommended [4]. Within the first 24 hours following severe TBI, hyperventilation should be avoided, as it can further compromise an already critically reduced cerebral perfusion. Coles et al. reported that, in patients with TBI, hyperventilation increases the volume of severely hypoperfused tissue within the injured brain, despite improvements in CPP and ICP.
These reductions in regional cerebral perfusion may represent regions of potentially ischemic brain tissue [59]. Excessive and prolonged hyperventilation results in cerebral vasoconstriction and ischemia. Thus, hyperventilation is recommended only as a temporizing measure to reduce an elevated ICP. A brief period (15-30 minutes) of hyperventilation, to a $\mathrm{PaCO}_{2} 30-35 \mathrm{~mm} \mathrm{Hg}$ is recommended to treat acute neurological deterioration reflecting increased ICP. Longer periods of hyperventilation might be required for intracranial hypertension refractory to all treatments including sedation, paralytics, CSF drainage, hypertonic saline solutions (HSSs) and osmotic diuretics. However, when hyperventilation is used, $\mathrm{SjvO}_{2}$ or $\mathrm{PbtO}_{2}$ measurements are recommended to monitor cerebral oxygenation and avoid cerebral ischemia.

The ventilatory settings should be adjusted to maintain a pulse oximetry $\left(\mathrm{SpO}_{2}\right)$ of $95 \%$ or greater and/or $\mathrm{PaO}_{2}$ of $80 \mathrm{~mm} \mathrm{Hg}$ or greater and to achieve normoventilation (eucapnia) with $\mathrm{PaCO}_{2}$ of 35 to $40 \mathrm{~mm} \mathrm{Hg}$. Mascia et al. reported that high tidal volume ventilation is an independent predictor and associated with acute lung injury (ALI) in patients with severe TBI [60]. Hence, protective ventilation with low tidal volume and moderate positive end-expiratory pressure (PEEP) has been recommended to prevent ventilator-associated lung injury and increased ICP [61].

Prior to suctioning the patient through the endotracheal tube (ETT), preoxygenation with a fraction of inspired oxygen $\left(\mathrm{FiO}_{2}\right)=1.0$, and administration of additional sedation are recommended to avoid desaturation and sudden increase in the ICP. Suctioning ETT must be brief and atraumatic.

It has been suggested that PEEP increases intrathoracic pressure leading to a decrease in cerebral venous drainage and consequently to an increase in CBV and ICP. However, the effect of PEEP on ICP is significant only with level of PEEP higher than $15 \mathrm{~cm} \mathrm{H}_{2} \mathrm{O}$ in hypovolemic patients. Nevertheless, the lowest level of PEEP, usually 5 to $8 \mathrm{~cm} \mathrm{H}_{2} \mathrm{O}$ that maintains adequate oxygenation and prevents end-expiratory collapse, should be used. Higher PEEP, up to $15 \mathrm{~cm} \mathrm{H}_{2} \mathrm{O}$, may be used in cases of refractory hypoxemia.

A significant number of patients with severe TBI develop ALI or acute respiratory distress syndrome (ARDS), with an incidence of ALI/ARDS reported between $10 \%$ and 30\% [62-64]. Etiology of ALI/ARDS in patients with severe TBI include aspiration, pneumonia, pulmonary contusion, massive blood transfusion, transfusion-related ALI (TRALI), sepsis, neurogenic pulmonary edema and use of high tidal volume and high respiratory rate $[65,66]$. Development of ALI/ARDS in patients with severe TBI is associated with longer ICU LOS and fewer ventilation free days [60]. Ventilatory 
management of patients with severe TBI and ALI/ARDS is challenging. A balanced ventilation strategy, between the guidelines for severe TBI or the historical "brain injury" approach (adequate oxygenation: optimizing oxygenation-preserving cerebral venous drainage by using low levels of PEEP, and mild hypocapnia by using high tidal volume), and the lung protective ventilation strategy (by using high PEEP and low tidal volume), is desired, however, is difficult to achieve. Permissive hypercapnia, an acceptable strategy in patients with ALI/ARDS, should be avoided, if possible, in patients with severe TBI because of the associated cerebral vasodilatation, increased CBV and ICP.

\section{Hemodynamic support}

Hemodynamic instability is common in patients with severe TBI. Hypotension, defined as SBP $<90 \mathrm{~mm} \mathrm{Hg}$ or MAP $<65 \mathrm{~mm} \mathrm{Hg}$, is a frequent and detrimental secondary systemic brain insult and has been reported to occur in up to $73 \%$ during ICU stay [67]. Studies from the Traumatic Coma Data Bank (TCDB) documented that hypotension is a major determinant and an independent predictor of outcome of severe TBI (68). Hypotension is significantly associated with increased mortality following TBI [69-71]. Among predictors of outcome of TBI, hypotension is the most amenable to prevention, and should be scrupulously avoided and aggressively managed.

It is unlikely that an isolated TBI by itself would cause hypotension unless the patient has become brain dead. Intravascular volume depletion due to hemorrhage from associated injuries such as scalp, neck, vessels, chest, abdomen, pelvis and extremities, or due to polyuria secondary to diabetes insipidus, are the most common causes of hypotension in patients with severe TBI. Other potential reasons for hypotension in patients with severe TBI are myocardial contusion resulting in primary pump failure, and spinal cord injury with spinal shock (cervical lesions cause total loss of sympathetic innervation and lead to vasovagal hypotension and bradyarrythmias). An often missed cause of hypotension in patients with TBI is the use of etomidate for intubation. It has been reported that even a single dose of etomidate may cause adrenal insufficiency resulting in hypotension [72].

Appropriately aggressive fluid administration to achieve adequate intravascular volume is the first step in resuscitating a patient with hypotension following severe TBI. The CVP may be used to guide fluid management and is recommended to be maintained at $8-10 \mathrm{~mm}$ $\mathrm{Hg}$. In patients who respond poorly to adequate volume expansion and vasopressors, demonstrate hemodynamic instability, or have underlying cardiovascular disease, a pulmonary artery catheter or non-invasive hemodynamic monitoring may be considered. The pulmonary capillary wedge pressure should be maintained at $12-15 \mathrm{~mm}$ $\mathrm{Hg}$. Several reliable predictors of fluid responsiveness such as pulse pressure variation, systolic pressure variation, stroke volume variation, and collapse of inferior vena cava have been suggested to guide fluid management. Isotonic crystalloids, specifically normal saline (NS) solution are the fluid of choice for fluid resuscitation and volume replacement. HSSs are effective for blood pressure restoration in hemorrhagic shock; however, with no survival benefit [73]. The National Heart, Lung, and Blood Institute of the National Institutes of Health has stopped enrollment into a clinical trial testing the effects of HSSs on patients with severe TBI because HSS was no better than the standard treatment of NS [74]. Blood and blood products may be used as appropriate.

Anemia is a common secondary systemic brain insult and should be avoided, with a targeted hemoglobin $\geq 100 \mathrm{~g} / \mathrm{L}$ or hematocrit $\geq 0.30$. Brain tissue is reach in thromboplastin and cerebral damage may cause coagulopathy [75]. Coagulation abnormalities should be aggressively corrected with blood products as appropriate, especially in the presence of a traumatic intracranial hemorrhage.

Prior to the insertion of an ICP monitoring, a MAP $\geq 80 \mathrm{~mm} \mathrm{Hg}$ is recommended. The rationale for a MAP $\geq 80 \mathrm{~mm} \mathrm{Hg}$ is to maintain a CPP $\geq 60 \mathrm{~mm} \mathrm{Hg}$ for a treatment threshold of ICP $>20 \mathrm{~mm} \mathrm{Hg}$ [4]. Following the insertion of an ICP monitoring, the management of MAP will be directed by the ICP/CPP values.

Occasionally, targeted CPP or MAP may not be achieved despite appropriate fluid resuscitation and adequate intravascular volume. Excessive and inappropriate fluid administration to achieve intended CPP or MAP is associated with fluid overload and ARDS, and should be avoided. Vasopressors should be used to achieve targeted CPP or MAP if these could not be obtained with adequate fluid resuscitation. Norepinephrine, titrated through a central venous line (CVL), is recommended. Dopamine causes cerebral vasodilatation and increase ICP, however, can be used initially via a peripheral intravenous cannula until a CVL is inserted $[76,77]$. Phenylephrine, a pure alpha-agonist vasoactive agent, is recommended in TBI patients with tachycardia. A recent study reported that patients who received phenylephrine had higher MAP and CPP than patients who received dopamine and norepinephrine, respectively [78].

Hypertension, defined as SBP $>160 \mathrm{~mm} \mathrm{Hg}$ or MAP $>110 \mathrm{~mm} \mathrm{Hg}$, is also a secondary systemic brain insult that can aggravate vasogenic brain edema and intracranial hypertension. However, hypertension may be a physiological response to a reduced cerebral perfusion. Consequently, and prior to ICP monitoring, 
hypertension should not be treated unless a cause has been excluded or treated, and SBP $>180-200 \mathrm{~mm} \mathrm{Hg}$ or MAP > 110-120 mm Hg. Lowering an increased BP, as a compensatory mechanism to maintain an adequate CPP, exacerbates cerebral ischemia. Following placement of an ICP monitoring, the management of MAP is guided by the CPP.

\section{Cerebral perfusion pressure}

Cerebral ischemia is considered the single most important secondary event affecting outcome following severe TBI. CPP, defined as the MAP minus ICP, $(C P P=$ MAP - ICP), below $50 \mathrm{~mm} \mathrm{Hg}$ should be avoided [4]. A low CPP may jeopardize regions of the brain with pre-existing ischemia, and enhancement of CPP may help to avoid cerebral ischemia. The CPP value to target should be maintained above the ischemic threshold at a minimum of $60 \mathrm{~mm} \mathrm{Hg}$ [4]. Maintenance of a CPP greater than $60 \mathrm{mmHg}$ is a therapeutic option that may be associated with a substantial reduction in mortality and improvement in quality of survival, and is likely to enhance perfusion to ischemic regions of the brain following severe TBI. There is no evidence that the incidence of intracranial hypertension, morbidity, or mortality is increased by the active maintenance of CPP above $60 \mathrm{mmHg}$ with normalizing the intravascular volume or inducing systemic hypertension. Both $60 \mathrm{~mm}$ $\mathrm{Hg}$ and $70 \mathrm{~mm} \mathrm{Hg}$ are cited in the literature as the threshold above which CPP should be maintained. The CPP should be maintained at a minimum of $60 \mathrm{~mm} \mathrm{Hg}$ in the absence of cerebral ischemia, and at a minimum of $70 \mathrm{~mm} \mathrm{Hg}$ in the presence of cerebral ischemia [4]. $\mathrm{PbtO}_{2}$ monitoring has been suggested to identify individual optimal CPP [79]. In the absence of cerebral ischemia, aggressive attempts to maintain CPP above $70 \mathrm{~mm}$ $\mathrm{Hg}$ with fluids and vasopressors should be avoided because of the risk of ARDS [4].

\section{Hyperosmolar therapy}

Mannitol administration is an effective method to decrease raised ICP after severe TBI [80]. Mannitol creates a temporary osmotic gradient and it increases the serum osmolarity to 310 to $320 \mathrm{mOsm} / \mathrm{kg} \mathrm{H} \mathrm{H}_{2} \mathrm{O}$. The prophylactic administration of mannitol is not recommended [4]. Prior to ICP monitoring, mannitol use should be restricted to patients with signs of transtentorial herniation or progressive neurologic deterioration not attributable to extracranial causes. Arbitrarily, mannitol should not be administered if serum osmolarity is $>320 \mathrm{mOsm} / \mathrm{kg} \mathrm{H}_{2} \mathrm{O}$. Osmotic diuresis should be compensated by adequate fluid replacement with isotonic saline solution to maintain euvolmia. The effective dose is $0.25-1 \mathrm{~g} / \mathrm{kg}$, administered intravenously over a period of 15 to 20 minutes. The regular administration of mannitol may lead to intravascular dehydration, hypotension, pre-renal azotemia and hyperkalemia [81]. Mannitol may pass and accumulate in the brain, causing a reverse osmotic shift or rebound effect, and raising brain osmolarity, thus increasing ICP $[82,83]$. Mannitol is contraindicated in patients with TBI and renal failure because of the risk of pulmonary edema and heart failure.

HSSs have been suggested as alternative to mannitol. HSS has a number of beneficial effects in head-injured patients, including expansion of intravascular volume, extraction of water from the intracellular space, decrease in ICP, and increase in cardiac contractility. HSS produces osmotic dehydration and viscosity-related cerebral vasoconstriction. Prolonged administration of a HSS was associated with lowered ICP, controlled cerebral edema, with no adverse effects of supraphysiologic hyperosmolarity such as renal failure, pulmonary edema, or central pontine demyelination $[84,85]$. In a recent meta-analysis, Kamel et al. found that hypertonic saline is more effective than, and may be superior to the current standard of care which is, mannitol for the treatment of elevated ICP [86].

\section{Temperature Modulation}

Moderate systemic hypothermia at $32^{\circ} \mathrm{C}$ to $34^{\circ} \mathrm{C}$, reduces cerebral metabolism and $\mathrm{CBV}$, decreases ICP, and increases CPP [87]. Evidence of the impact of moderate hypothermia on the outcome of patients with TBI was controversial. Initially, studies showed that moderate hypothermia, established on admission, was associated with significantly improved outcome at 3 and 6 months after TBI [88]. However, in a large RCT, no effect of moderate hypothermia has been demonstrated on outcome after TBI $[89,90]$. The National Acute Brain Injury Study: Hypothermia II was a randomized, multicentre clinical trial of patients with severe TBI who were enrolled within 2 to 5 hours of injury. Patients were randomly assigned to hypothermia (cooling to $33^{\circ}$ $\mathrm{C}$ for 48 hours) or normothermia. There was no significant difference in outcomes between the hypothermia and the normothermia groups. The trial did not confirm the utility of hypothermia as a primary neuroprotective strategy in severe TBI patients [88]. However, temperature should be controlled and fever should be aggressively treated in patients with severe TBI. Moderate hypothermia may be used in refractory, uncontrolled ICP.

\section{Antiseizure prophylaxis}

Post-traumatic seizures are classified as early occurring within 7 days of injury, or late occurring after 7 days following injury [91]. Prophylactic therapy (phenytoin, carbamazepine, or phenobarbital) is not recommended for preventing late post-traumatic seizures [4]. However, the BTF recommended prophylaxis therapy to prevent early post-traumatic seizure in TBI patients who are at high risk for seizures [4]. The risk factors include: GCS score $<10$, cortical contusion, depressed skull fracture, 
subdural hematoma, epidural hematoma, intracerebral hematoma, penetrating TBI, and seizures within 24 hours of injury $[4,92]$.

Phenytoin is the recommended drug for the prophylaxis of early post-traumatic seizures. A loading dose of 15 to $20 \mathrm{mg} / \mathrm{kg}$ administered intravenously (I.V.) over 30 minutes followed by $100 \mathrm{mg}$, I.V., every 8 hours, titrated to plasma level, for 7 days, is recommended. Patients receiving antiseizures prophylaxis should be monitored for potential side effects.

\section{Deep vein thrombosis prophylaxis}

Severe TBI patients are at significantly high risk of developing venous thromoembolic events (VTEs) including deep vein thrombosis (DVT) and pulmonary embolism. The risk of developing DVT in the absence of prophylaxis was estimated to be $20 \%$ after severe TBI [93].

Mechanical thromboprophylaxis, including graduated compression stockings and sequential compression devices, are recommended unless their use is prevented by lower extremity injuries. The use of such devices should be continued until patients are ambulatory. In the absence of a contraindication, low molecular weight heparin (LMWH) or low dose unfractionated heparin should be used in combination with mechanical prophylaxis. However, the use of pharmacological prophylaxis is associated with an increased risk for expansion of intracranial hemorrhage. Although, evidence to support recommendations regarding the timing of pharmacological prophylaxis is lacking, most experts suggest initiating pharmacologic prophylaxis as early as 48 to 72 hours after the injury, in the absence of other contraindications [94].

\section{Stress ulcer prophylaxis}

Severe TBI is a well-known risk factor for stress ulcers (Cushing's ulcer) in the ICU. Prophylaxis includes early enteral feeding, and pharmacological prophylaxis such as $\mathrm{H} 2$ - blockers, proton-pump inhibitors and sucralfate $[95,96]$.

\section{Nutritional support}

Severe TBI patients are usually in hypermetabolic, hypercatabolic and hyperglycemic state, with altered G.I. functions. There is evidence suggesting that malnutrition increases mortality rate in TBI patients [97]. Studies documented the superiority of enteral feeding over parenteral nutrition (PN). Use of PN should be limited to contraindications of enteral feeding, as it is associated with complications and an increased mortality [98]. Hence, early enteral feeding is recommended in patients with severe TBI, as it is safe, cheap, cost-effective, and physiologic. The potential advantages of enteral feeding include stimulation of all gastro-intestinal tract functions, preservation of the immunological gut barrier function and intestinal mucosal integrity, and reduction of infections and septic complications. Frequently, patients with severe TBI have gastric feeding intolerance due to many reasons including abnormal gastric emptying and altered gastric function secondary to increased ICP, and use of opiates. Prokinetic agents such as metoclopramide or erythromycin, improve tolerance. Postpyloric feeding avoids gastric intolerance and allows higher caloric and nitrogen intake.

Although, the BTF recommended $140 \%$ of resting metabolic expenditure in non-paralyzed patients and $100 \%$ in paralyzed patients to be replaced, there is growing body of evidence suggesting the benefit of a lower caloric intake [99-102].

\section{Glycemic control}

In patients with severe TBI, stress hyperglycemia is a common secondary systemic brain insult. Studies showed that hyperglycemia has repeatedly been associated with poor neurological outcome after TBI [103-108]. Although hyperglycaemia is detrimental, maintaining low blood glucose levels within tight limits is controversial in patients with severe TBI, because hypoglycemia, a common complication of tight glucose control, can induce and aggravate underlying brain injury [109]. Vespa et al. reported that intensive insulin therapy (IIT) results in a net reduction in microdialysis glucose and an increase in microdialysis glutamate and lactate/pyruvate ratio without conveying a functional outcome advantage [110]. Oddo et al. documented that tight systemic glucose control is associated with reduced cerebral extracellular glucose availability and increased prevalence of brain energy crisis, which in turn correlates with increased mortality. IIT may impair cerebral glucose metabolism after severe brain injury [111]. A recent meta-analysis on IIT in brain injury revealed that IIT did not appear to decrease the risk of in-hospital or late mortality $(\mathrm{RR}=1.04,95 \% \mathrm{CI}=0.75,1.43$ and $\mathrm{RR}=$ $1.07,95 \% \mathrm{CI}=0.91,1.27$ respectively). Moreover, IIT did not have a protective effect on long-term neurological outcomes $(R R=1.10,95 \% C I=0.96,1.27)$. However, IIT increased the rate of hypoglycemic episodes (RR = $1.72,95 \% \mathrm{CI}=1.20,2.46)$ [112]. Consequently, the majority of currently available clinical evidence does not support tight glucose control (maintenance of blood glucose levels below 110-120 mg/dl) during the acute care of patients with severe TBI [113].

\section{Steroids}

Steroids administration is not recommended for improving the outcome or reducing ICP in patients with severe TBI. Moreover, steroids may be harmful after TBI. The CRASH trial, a multicentre international collaboration, aimed to confirm or refute such an effect by recruiting 20000 patients. In May, 2004, the data monitoring committee disclosed the unmasked results to the steering committee, which stopped recruitment at 10008 
patients. Compared with placebo, the risk of death from all causes within 2 weeks was higher in the group allocated corticosteroids (1052 [21.1\%] vs. 893 [17.9\%] deaths; relative risk $=1.18[95 \% \mathrm{CI}=1.09-1.27] ; \mathrm{p}=$ 0.0001 ). The authors concluded that there was no reduction in mortality with methylprednisolone in the 2 weeks after head injury. The cause of the rise in risk of death within 2 weeks was unclear [114]. Hence, in patients with severe TBI, high-dose methylprednisolone is contraindicated [4].

\section{Barbiturate coma}

Barbiturate is proven as efficient therapy for refractory intracranial hypertension. Barbiturates reduce cerebral metabolism and CBF, and lower ICP [115]. High-dose barbiturate may be considered in hemodynamically stable, severe TBI patients with refractory to maximal medical and surgical ICP lowering therapy. Their main side effects are: hypotension, especially in volume depleted patients; and immunosuppression with an increased infection rate [116]. However, prophylactic administration of barbiturate to induce burst suppression EEG is not recommended [4]. Pentobarbital is recommended for the induction of barbiturate coma as follows:

Pentobarbital: $10 \mathrm{mg} / \mathrm{kg}$ over $30 \mathrm{~min}$, then

$5 \mathrm{mg} / \mathrm{kg} / \mathrm{h}$ for 3 hours, then

$1 \mathrm{mg} / \mathrm{kg} / \mathrm{h}$

As alternative, sodium thiopental might be used as follows:

$2.5-10 \mathrm{mg} / \mathrm{kg} \mathrm{IV}$, slow bolus, then

$0.5-2 \mathrm{mg} / \mathrm{kg} / \mathrm{h}$

\section{Fluids and electrolytes}

The goal of fluid management is to establish and maintain euvolemia to moderate hypervolemia (CVP $=8-10$ $\mathrm{mm} \mathrm{Hg}$; PCWP $=12-15 \mathrm{~mm} \mathrm{Hg}$ ). Negative fluid balance has been shown to be associated with an adverse effect on outcome, independent of its relationship to ICP, MAP, or CPP [117]. Isotonic crystalloids should be used for fluid management, and normal saline (NS) is the recommended solution. Aggressive fluid resuscitation with NS may result in hyperchloremic metabolic acidosis, a predictable and important consequence of large-volume, saline-based intravenous fluid administration, with different clinical implications. Hypotonic solutions, such as $1 / 2$ NS, 1/4 NS, Dextrose $5 \%$ in water (D5\%W), D5\% 1/2 NS, or D5\% 1/4 NS should be avoided. Ringer's lactate solution is slightly hypotonic and is not preferred for fluid resuscitation in severe TBI patients, particularly for large volume resuscitation, as it may decrease serum osmolarity. Glucose containing solutions, as above or $\mathrm{D} 10 \% \mathrm{~W}$ should be avoided in the first 24 to 48 hours, unless the patient develops hypoglycemia in the absence of nutritional support. In addition to the detrimental effects of hyperglycemia in TBI, anaerobic cerebral metabolism of glucose produces acidosis and free water; both would worsen the brain edema. The use of colloids should be very cautious as it was reported, in the SAFE trial, to be associated with increased mortality in patients with TBI [118]. HSSs have been shown to be effective in decreasing brain edema, reducing elevated ICP, and increasing MAP and CPP [119]. Other potential benefits of HSSs include faster expansion of intravascular volume (with small volumes), increased cardiac output and pulmonary gas exchange, reversal of immunomodulation caused by hypotension, and decreased CSF production. HSS is also associated with potential side effects including sudden hypertension, hypernatremia, altered consciousness and seizures. However, the overall results of HSS related studies are inconsistent and further clinical trials are needed to define its role.

In severe TBI patients with increased ICP or brain edema, a serum sodium level $\mathrm{Na}^{+}$up to $150-155 \mathrm{mEq} /$ L may be acceptable [120]. However, serum electrolytes disturbances are common complications after TBI. Injury to the hypothalamic-pituitary system is a major contributing factor. The most common causes for hypernatremia $\left(\mathrm{Na}^{+}>150 \mathrm{mmol} / \mathrm{L}\right)$ in patients with TBI are central or neurogenic diabetes insipidus, osmotic diuresis (mannitol), and the use of HSS. Correction of severe hypernatremia $\left(\mathrm{Na}^{+}>160 \mathrm{mmol} / \mathrm{L}\right)$ should be gradual, as abrupt changes in serum osmolarity and rapid fall of serum sodium concentration would worsen cerebral edema. Fluid resuscitation of hypovolemic hypernatremic TBI patients should be initially only with NS. Management of electrolytes disturbances should follow complete volume restoration. Hyponatremia is detrimental and major secondary systemic brain insult in patients with severe TBI, as it leads to exacerbation of brain edema and an increase in ICP. It is usually secondary to cerebral salt wasting syndrome [121], or to the syndrome of inappropriate anti-diuretic hormone secretion (SIADH). Hypophosphatemia and hypomagnesemia are common complications in head-injured patients and they lower the seizure threshold $[122,123]$.

\section{Lund therapy}

The "Lund therapy" of severe TBI is based on physiological principles for cerebral tissue and blood volume regulation. The therapy aims at preventing cerebral hypoxia simultaneously with taking measures that counteract transcapillary filtration. The Lund concept is more beneficial if the blood brain barrier is disrupted and more appropriate if pressure autoregulation is lost. The therapy has two main goals: first to reduce or 
prevent an increase in ICP (ICP-targeted goal), and second to improve perfusion and oxygenation around contusions (perfusion-targeted goal) by maintaining normal blood oxygenation, normovolemia and normal hematocrit. The treatment protocol, to reduce an increased ICP, includes preservation of a normal colloidal absorbing force (normal plasma protein concentrations), a reduction of intracapillary pressure through reduction of systemic blood pressure by antihypertensive therapy (a beta1-antagonist, metoprolol, combined with an alpha 2-agonist, clonidine) and a simultaneous, moderate constriction of precapillary resistance vessels with low-dose thiopental and dihydroergotamine. A few studies have reported that Lund therapy was associated with improved clinical outcome [124]

\section{General intensive care}

Similar to other patients in the intensive care, TBI victims should receive the usual daily care as follows:

- Raising head of bed to $30^{\circ}-45^{\circ}$ : that would reduce ICP and improves CPP [125]; and lower the risk of ventilator-associated pneumonia (VAP).

- Keeping the head and neck of the patient in a neutral position: this would improve cerebral venous drainage and reduce ICP.

- Avoiding compression of internal or external jugular veins with tight cervical collar or tight tape fixation of the endotracheal tube that would impede cerebral venous drainage and result in an increase in the ICP.

- Turning the patient regularly and frequently with careful observation of the ICP [126].

- Providing eye care, mouth and skin hygiene

- Implementing all evidence-based bundles for prevention of infection including VAP [127] and central line bundle [128].

- Administrating a bowel regimen to avoid constipation and increase of intra-abdominal pressure and ICP.

- Performing physiotherapy

\section{Decompressive craniectomy and hemicraniectomy}

Surgical decompressive craniectomy has been suggested as a promising therapeutic approach for patients with acute severe TBI at risk to develop severe brain edema. Decompressive craniectomy and hemicraniectomy, both are well accepted for the surgical treatment of intractable intracranial hypertension in cases in which medical management fails. Decompressive surgery is performed as a life-saving procedure when death is imminent from intracranial hypertension. Though the operation is being increasingly used, evidence regarding its overall effects on outcomes is contradicting. Albanèse et al, in a retrospective cohort study in 40 patients with intractable intracranial hypertension and at very high risk of brain death, decompressive craniectomy allowed $25 \%$ of patients to attain social rehabilitation at $1 \mathrm{yr}$ [129]. Cooper et al, in a prospective, randomized controlled trial in 155 adults with severe diffuse TBI and intracranial hypertension that was refractory to first-tier therapies, bifrontotemporoparietal decompressive craniectomy, as compared with standard care, was associated with decreased intracranial pressure $(\mathrm{P}<0.001)$ and length of stay in the ICU $(\mathrm{P}<0.001)$, however, with more unfavorable outcomes (odds ratio $=2.21 ; 95 \% \mathrm{CI}$ $=1.14-4.26 ; \mathrm{P}=0.02$ ). Rates of death at 6 months were similar in the craniectomy group (19\%) and the standard-care group (18\%) [130].

\section{Predicting outcome after TBI}

The early prediction of outcome after TBI is important. A few predictive models for patient outcomes after severe TBI have been proposed [131,132]. A relatively simple prognostic model using 7 predictive baseline characteristics including age, motor score, pupillary reactivity, hypoxia, hypotension, computed tomography classification, and traumatic subarachnoid hemorrhage has been reported to accurately predict 6 -month outcome in patients with severe or moderate TBI [131]. A predictive model based on age, absence of light reflex, presence of extensive subarachnoid hemorrhage, ICP, and midline shift was shown to have high predictive value and to be useful for decision making, review of treatment, and family counseling in case of TBI [132].

\section{Conclusion}

The management of severe TBI centers on meticulous and comprehensive intensive care that includes multimodel, protocolized approach involving careful hemodynamic support, respiratory care, fluid management, and other aspects of therapy, aimed at preventing secondary brain insults, maintaining an adequate CPP, and optimizing cerebral oxygenation. This approach clearly requires the efforts of a multidisciplinary team including neurointensivists, neurosurgeons, bedside nurses and respiratory therapists, and other members of the medical team. While such management can be challenging, it is by all means rewarding considering the age of the victims and the socio-economic impact of the problem.

\section{List of abbreviations}

BTF: Brain Trauma Foundation; CBF: Cerebral blood flow; CBV: Cerebral blood volume; CPP: Cerebral perfusion pressure; CSF: Cerebral spinal fluid; CVP:

Central venous pressure; EEG: Electroencephalogram; GCS: Glasgow coma scale; HSS: Hypertonic saline solution; ICP: Intracranial pressure; MAP: Mean arterial pressure; NS: Normal saline; $\mathrm{PbtO}_{2}$ : Brain tissue oxygen tension; PEEP: Positive end expiratory pressure; SBP: Systolic blood pressure; SIADH:

Syndrome of inappropriate anti-diuretic hormone secretion; $\mathrm{SjVO}_{2}$ : Jugular venous oxygen saturation; TBI: Traumatic brain injury. 


\section{Author details}

'Surgical Intensive Care Unit, Intensive Care Department, King Abdulaziz Medical City, PO Box 22490, Riyadh 11426, K.S.A. ${ }^{2}$ Intensive Care Department, College of Medicine, King Saud Bin Abdulaziz University for Health Sciences, King Abdulaziz Medical City, PO Box 22490, Riyadh 11426, K.S.A.

\section{Authors' contributions}

$\mathrm{SHH}$ performed literature review and wrote the initial draft of the manuscript. YMA edited and rewrote portions of the manuscript. All authors read and approved the final manuscript.

\section{Authors' information}

Samir H. Haddad, MD, is Head Section of Surgical Intensive Care Unit; and Consultant in the Intensive Care Department at King Abdulaziz Medical City, Riyadh, Saudi Arabia.

Yaseen M. Arabi, MD, FCCP, FCCM, is Chairman, Intensive Care Department; and Medical Director, Respiratory Services at King Abdulaziz Medical City, Riyadh, Saudi Arabia. He is also Associate Professor at College of Medicine, King Saud Bin Abdulaziz University for Health Sciences, Riyadh, Saudi Arabia.

\section{Competing interests}

The authors declare that they have no competing interests.

Received: 22 October 2011 Accepted: 3 February 2012

Published: 3 February 2012

\section{References}

1. Teasdale G, Jennett B: Assessment of coma and impaired consciousness: A practical scale. Lancet 1974, 2:81-84.

2. Bullock R, Chestnut RM, Clifton G, Ghajar J, Marion DW, Narayan RK, et al: Guidelines for the management of severe head injury. J Neurotrauma 1996, 13(11):643-734.

3. Bullock R, Chestnut RM, Clifton G, Ghajar J, Marion DW, Narayan RK, et al: Guidelines for the Management of Severe Traumatic Injury. J Neurotrauma 2000, 17:453-553.

4. Bullock R, et al: Guidelines for the Management of Severe Traumatic Brain Injury. J Neurotrauma, 3 2007, 24(Suppl 1):S1-S106.

5. Vukic M, Negovetic L, Kovac D, Ghajar J, Glavic Z, Gopcevic A: The effect of implementation of guidelines for the management of severe head injury on patient treatment and outcome. Acta Neurochir (Wien) 1999, 141(11):1203-8.

6. Hesdorffer D, Ghajar J, lacono L: Predictors of compliance with the evidence-based guidelines for traumatic brain injury care: A survey of United States trauma centers. J Trauma 2002, 52:1202-1209.

7. Fakhry SM, Trask AL, Waller MA, Watts DD: Management of brain- injured patients by an evidence-based medicine protocol improves outcomes and decreases hospital charges. J Trauma 2004, 56(3):492-499, discussion 499-500.

8. Arabi Y, Haddad S, Tamim H, Al-Dawood A, Al-Qahtani S, Ferayan A, et al: Mortality Reduction after Implementing a Clinical Practice GuidelinesBased Management Protocol for Severe Traumatic Brain Injury. I Crit Care 2010, 25(2):190-195.

9. Chesnut RM: Secondary brain insults after head injury: clinical perspectives. New Horiz 1995, 3:366-75.

10. Unterberg AW, Stover JF, Kress B, Kiening KL: Edema and brain trauma. Neuroscience 2004, 129:1021-9.

11. Jeremitsky E, Omert L, Dunham CM, Protetch J, Rodriguez A: Harbingers of poor outcome the day after severe brain injury: hypothermia, hypoxia, and hypoperfusion. J Trauma 2003, 54(2):312-319.

12. Abdoh MG, Bekaert O, Hodel J, Diarra SM, Le Guerinel C, Nseir R, BastujiGarin S, Decq P: Accuracy of external ventricular drainage catheter placement. Acta Neurochir (Wien) 2011.

13. Stiefel MF, Spiotta A, Gracias VH, Garuffe AM, Guillamondegui O, MaloneyWilensky E, Bloom S, Grady MS, LeRoux PD: Reduced mortality rate in patients with severe traumatic brain injury treated with brain tissue oxygen monitoring. J Neurosurg 2005, 103(5):805-811.

14. Saul TG, Ducker TB: Effect of intracranial pressure monitoring and aggressive treatment on mortality in severe head injury. J Neurosurg 1982, 56:498-503.

15. Saul TG, Ducker TB: Intracranial pressure monitoring in patients with severe head injury. Am Surg 1982, 48(9):477-480.
16. Eisenberg HM, Frankowski RF, Contant CF, et al: High-dose barbiturate control of elevated intracranial pressure in patients with severe head injury. J Neurosurg 1988, 69:15-23.

17. Howells $T$, Elf $K$, Jones $P$, et al: Pressure reactivity as a guide in the treatment of cerebral perfusion pressure in patients with brain trauma. $J$ Neurosurg 2005, 102:311-317.

18. Aarabi B, Hesdorffer D, et al: Outcome following decompressive craniectomy for malignant swelling due to severe head injury. J Neurosurg 2006, 104:469-479.

19. Timofeev I, Kirkpatrick P, Corteen E, et al: Decompressive craniectomy in traumatic brain injury: outcome following protocol-driven therapy. Acta Neurochir (Suppl) 2006, 96:11-16.

20. Bulger EM, Nathens AB, Rivara FP, Moore M, Mackenzie EJ, Jurkovich GJ: Management of severe head injury: institutional variations in care and effect on outcome. Crit Care Med 2002, 30:1870-1876.

21. Lane PL, Skoretz TG, Doig G, Girotti MJ: Intracranial pressure monitoring and outcomes after traumatic brain injury. Can J Surg 2000, 43:442-448.

22. Mauritz W, Steltzer H, Bauer P, Dolanski-Aghamanoukjan L, Metnitz P: Monitoring of intracranial pressure in patients with severe traumatic brain injury: an Austrian prospective multicenter study. Intensive Care Med 2008, 34:1208-1215.

23. Stocchetti N, Penny KI, Dearden M, Braakman R, Cohadon F, lannotti F, Lapierre F, Karimi A, Maas A Jr, Murray GD, Ohman J, Persson L, Servadei F, Teasdale GM, Trojanowski T, Unterberg A, European Brain Injury Consortium: Intensive care management of head-injured patients in Europe: a survey from the European brain injury consortium. Intensive Care Med 2001, 27:400-406.

24. Cremer OL, van Dijk $G$, van Wensen $E$, et al: Effect of intracranial pressure monitoring and targeted intensive care on functional outcome after severe head injury. Crit Care Med 2005, 33:2207-2213.

25. Cremer OL: Does ICP monitoring make a difference in neurocritical care? European Journal of Anaesthesiology 2008, 25(Suppl 42):87-93.

26. Shafi S, Diaz-Arrastia R, Madden C, Gentilello L: Intracranial pressure monitoring in brain-injured patients is associated with worsening of survival. J Trauma 2008, 64(2):335-340.

27. Haddad S, AlDawood AS, AlFerayan A, Russell N, Tamim H, Arabi YM: Relationship between intracranial pressure monitoring and outcomes in severe traumatic brain injury patients. Anaesth Intensive Care 2011, 39(6):1043-1050

28. Forsyth $R$, Wolny $S$, Rodrigues $B$ : Routine intracranial pressure monitoring in acute coma. Cochrane Database Syst Rev 2010, , 2: CD002043.

29. Treggiari MM, Schutz N, Yanez ND, Romand JA: Role of intracranial pressure values and patterns in predicting outcome in traumatic brain injury: a systematic review. Neurocrit Care 2007, 6(2):104-12.

30. Robertson CS, Narayan RK, Gokaslan ZL, et al: Cerebral arteriovenous oxygen difference as an estimate of cerebral blood flow in comatose patients. J Neurosurg 1989, 70:222-230.

31. Lam JM, Chan MS, Poon WS: Cerebral venous oxygen saturation monitoring: is dominant jugular bulb cannulation good enough? $\mathrm{Br} J$ Neurosurg 1996, 10:357-364.

32. Cruz J: The first decade of continuous monitoring of jugular bulb oxyhemoglobin saturation: management strategies and clinical outcome. Crit Care Med 1998, 26:344-351.

33. Robertson CS, Cormio M: Cerebral metabolic management. New Horiz 1995, 3:410-422.

34. Sheinberg M, Kanter MJ, Robertson CS, et al: Continuous monitoring of jugular venous oxygen saturation in head-injured patients. I Neurosurg 1992, 76:212-217.

35. Gopinath SP, Robertson CS, Contant CF, et al: Jugular venous desaturation and outcome after head injury. J Neurol Neurosurg Psychiatry 1994, 57:717-723.

36. Robertson CS, Gopinath SP, Goodman JC, Contant CF, Valadka AB, Narayan RK: $\mathrm{SjvO}_{2}$ monitoring in head-injured patients. J Neurotrauma 1995, 12:891-896.

37. Lewis SB, Myburgh JA, Reilly PL: Detection of cerebral venous desaturation by continuous jugular bulb oximetry following acute neurotrauma. Anaesth Intensive Care 1995, 23:307-314.

38. Rosenthal G, Hemphill JC, Sorani M, Martin C, Morabito D, Obrist WD, Manley GT: Brain tissue oxygen tension is more indicative of oxygen diffusion than oxygen delivery and metabolism in patients with traumatic brain injury. Crit Care Med 2008, 36(6):1917-1924. 
39. Meixensberger J, Dings J, Kuhnigk H, Roosen K: Studies of tissue pO2 in normal and pathological human brain cortex. Acta Neurochir Suppl (Wien) 1993, 59:58-63.

40. Stiefel MF, Spiotta A, Gracias VH, Garuffe AM, Guillamondegui O, MaloneyWilensky E, Bloom S, Grady MS, LeRoux PD: Reduced mortality rate in patients with severe traumatic brain injury treated with brain tissue oxygen monitoring. J Neurosurg 2005, 103:805-811.

41. Narotam PK, Morrison JF, Nathoo N: Brain tissue oxygen monitoring in traumatic brain injury and major trauma: outcome analysis of a brain tissue oxygen-directed therapy. J Neurosurg 2009, 111(4):672-682.

42. Spiotta AM, Stiefel MF, Gracias VH, Garuffe AM, Kofke WA, MaloneyWilensky E, Troxel AB, Levine JM, Le Roux PD: Brain tissue oxygen-directed management and outcome in patients with severe traumatic brain injury. J Neurosurg 2010, 113(3):571-580.

43. Nangunoori R, Maloney-Wilensky E, Stiefel M, Park S, Andrew Kofke W, Levine JM, Yang W, Le Roux PD: Brain Tissue Oxygen-Based Therapy and Outcome After Severe Traumatic Brain Injury: A Systematic Literature Review. Neurocrit Care 2011.

44. Oddo M, Levine JM, Mackenzie L, Frangos S, Feihl F, Kasner SE, Katsnelson M, Pukenas B, Macmurtrie E, Maloney-Wilensky E, Kofke WA, LeRoux PD: Brain hypoxia is associated with short-term outcome after severe traumatic brain injury independently of intracranial hypertension and low cerebral perfusion pressure. Neurosurgery 2011, 69(5):1037-45, discussion 1045

45. Bhatia A, Gupta AK: Neuromonitoring in the intensive care unit. II. Cerebral oxygenation monitoring and microdialysis. Intensive Care Med 2007, 33(8):1322-1328.

46. Leal-Noval SR, Cayuela A, Arellano-Orden V, Marín-Caballos A, Padilla V, Ferrándiz-Millón C, Corcia Y, García-Alfaro C, Amaya-Villar R, MurilloCabezas F: Invasive and noninvasive assessment of cerebral oxygenation in patients with severe traumatic brain injury. Intensive Care Med 2010, 36(8):1309-1317

47. Tisdall MM, Smith M: Cerebral microdialysis: research technique or clinical tool. Br J Anaesth 2006, 97:18-25.

48. Stahl N, Mellergard P, Hallstrom A, Ungerstedt U, Nordstrom $\mathrm{CH}$ : ntracerebral microdialysis and bedside biochemical analysis in patients with fatal traumatic brain lesions. Acta Anaesthesiol Scand 2001, 45:977-985.

49. Zauner A, Doppenberg E, Woodward JJ, Choi SC, Young HF, Bullock R: Continuous monitoring of cerebral substrate delivery and clearance: initial experience in 24 patients with severe acute brain injuries. Neurosurgery 1997, 41:1082-1091.

50. Ragauskas A, Daubaris G, Dziugys A, et al: Innovative non-invasive method for absolute intracranial pressure measurement without calibration. Acta Neurochir Supp/ 2005, 95:357-361.

51. Bellner J, Romner B, Reinstrup P, et al: Transcranial Doppler sonography pulsatility index (PI) reflects intracranial pressure (ICP). Surg Neurol 2004 62:45-51.

52. de Freitas GR, Andre C: Sensitivity of transcranial Doppler for confirming brain death: A prospective study of 270 cases. Acta Neurol Scand 2006, 113:426-432

53. Dosemeci $L$, Dora B, Yilmaz $M$, et al: Utility of transcranial Doppler ultrasonography for confirmatory diagnosis of brain death: Two sides of the coin. Transplantation 2004, 77:71-75.

54. Sloan TB: Electrophysiologic monitoring in head injury. New Horiz 1995, 3:431-438.

55. Gutling E, Gonser A, Imhof $H G$, et al: EEG reactivity in the prognosis of severe head injury. Neurology 1995, 45:915-918.

56. Lewis SB, Myburgh JA, Thornton EL, Reilly PL: Cerebral oxygenation monitoring by near-infrared spectroscopy is not clinically useful in patients with severe closed-head injury: A comparison with jugular venous bulb oximetry. Crit Care Med 1996, 24:1334-1338.

57. Stewart C, Haitsma I, Zador Z, Morabito D, Manley G, Rosenthal G, Hemphill JC: The New Licox Combined Brain Tissue Oxygen and Brain Temperature Monitor: Assessment of in Vitro Accuracy and Clinical Experience in Severe Traumatic Brain Injury. Neurosurgery 2008, 63(6):1159-1165.

58. Zeiner A, Klewer J, Sterz F, Haugk M, Krizanac D, Testori C, Losert H, Ayati S, Holzer M: Non-invasive continuous cerebral temperature monitoring in patients treated with mild therapeutic hypothermia: an observational pilot study. Resuscitation 2010, 81(7):861-866.
59. Coles JP, Minhas PS, Fryer TD, Smielewski P, Aigbirihio F, Donovan T Downey SP, Williams G, Chatfield D, Matthews JC, Gupta AK, Carpenter TA, Clark JC, Pickard JD, Menon DK: Effect of hyperventilation on cerebral blood flow in traumatic head injury: clinical relevance and monitoring correlates. Crit Care Med 2002, 30(9):1950-1959.

60. Mascia L, Zavala E, Bosma K, Pasero D, Decaroli D, Andrews P, Isnardi D, Davi A, Arguis MJ, Berardino M, Ducati A, Brain IT group: High tidal volume is associated with the development of acute lung injury after severe brain injury: an international observational study. Crit Care Med 2007, 35(8):1815-1820

61. Mascia L, Grasso S, Fiore T, Bruno F, Berardino M, Ducati A: Cerebropulmonary interactions during the application of low levels of positive end-expiratory pressure. Intensive Care Med 2005, 31(3):373-379.

62. Holland MC, Mackersie RC, Morabito D, et al: The development of acute lung injury is associated with worse neurologic outcome in patients with severe traumatic brain injury. J Trauma 2003, 55:106-111.

63. Contant CF, Valadka AB, Gopinath SP, et al: Adult respiratory distress syndrome: A complication of induced hypertension after severe head injury. J Neurosurg 2001, 95:560-568.

64. Bratton $S L$, Davis RL: Acute lung injury in isolated traumatic brain injury. Neurosurgery 1997, 40:707-712.

65. Mascia L, Zavala E, Bosma K, Pasero D, Decaroli D, Andrews P, Isnardi D, Davi A, Arguis MJ, Berardino M, Ducati A, on behalf of the Brain IT group: High Tidal Volume is Associated With the Development of Acute Lung Injury After Severe Brain Injury: An International Observational Study. Crit Care Med 2007, 35:1815-1820

66. Gajic O, Dara SI, Mendez JL, et al: Ventilator-associated lung injury in patients without acute lung injury at the onset of mechanical ventilation. Crit Care Med 2004, 32:1817-1824.

67. Chesnut RM, Marshall SB, Piek J, Blunt BA, Klauber MR, Marshall LF: Early and late systemic hypotension as a frequent and fundamental source of cerebral ischemia following severe brain injury in the Traumatic Coma Data Bank. Acta Neurochir Suppl (Wien) 1993, 59:121-125

68. Chesnut RM, Marshall LF, Klauber MR, Blunt BA, Baldwin N, Eisenberg HM, Jane JA, Marmarou A, Foulkes MA: The role of secondary brain injury in determining outcome from severe head injury. J Trauma 1993, 34:216-222.

69. Manley G, Knudson MM, Morabito D, Damron S, Erickson V, Pitts L: Hypotension, hypoxia, and head injury: frequency, duration, and consequences. Arch Surg 2001, 136:1118-1123.

70. Marmarou A, Ward JD, Young HF, et al: Impact of ICP instability and hypotension on outcome in patients with severe head trauma. $J$ Neurosurg 1991, 75(Suppl):S59-S66.

71. Pietropaoli JA, Rogers FB, Shackford SR, Wald SL, Schmoker JD, Zhuang J: The deleterious effects of intraoperative hypotension on outcome in patients with severe head injuries. J Trauma 1992, 33(3):403-407.

72. Schulz-Stübner S: Sedation in traumatic brain injury: avoid etomidate. Crit Care Med 2005, 33(11):2723.

73. Strandvik GF: Hypertonic saline in critical care: a review of the literature and guidelines for use in hypotensive states and raised intracranial pressure. Anaesthesia 2009, 64(9):990-1003.

74. NHLBI Stops Enrollment in Study of Concentrated Saline for Patients with Traumatic Brain Injury. [http://www.nih.gov/news/health/may2009/ nhlbi-12.htm].

75. Schöchl H, Solomon C, Traintinger S, Nienaber U, Tacacs-Tolnai A, Windhofer C, Bahrami S, Voelckel W: Thromboelastometric (ROTEM) findings in patients suffering from isolated severe traumatic brain injury. J Neurotrauma 2011, 28(10):2033-2041.

76. Ract C, Vigue B: Comparison of the cerebral effects of dopamine and norepinephrine in severe head injury patients. Intensive Care Med 2001, 27:101-106.

77. Steiner LA, Andrew J, Czosnyka M, Chatfield DA, Salvador R, Coles JP, Gupta AK, Pickard JD, Menon DK: Direct comparison of cerebrovascular effects of norepinephrine and dopamine in head-injured patients. Crit Care Med 2004, 32:1049-1054

78. Sookplung P, Siriussawakul A, Malakouti A, Sharma D, Wang J, Souter MJ, Chesnut RM, Vavilala MS: Vasopressor use and effect on blood pressure after severe adult traumatic brain injury. Neurocrit Care 2011, 15(1):46-54.

79. Jaeger M, Dengl M, Meixensberger J, Schuhmann MU: Effects of cerebrovascular pressure reactivity-guided optimization of cerebral 
perfusion pressure on brain tissue oxygenation after traumatic brain injury. Crit Care Med 2010, 38(5):1343-1347.

80. Muizelaar JP, Lutz HA, Becker DP: Effect of mannitol on ICP and CBF and correlation with pressure autoregulation in severely head-injured patients. J Neurosurg 1984, 61:700-706.

81. Manninen PH, Lam AM, Gelb AW, Brown SC: The effect of high dose mannitol on serum and urine electrolytes and osmolality in neurosurgical patients. Can J Anaesth 1987, 34:442-446.

82. Marshall LF, Smith RW, Rauscher LA, Shapiro HM: Mannitol dose requirements in brain-injured patients. J Neurosurg 1978, 48:169-172.

83. Wise BL, Perkins RK, Stevenson E, Scott KG: Penetration of C14-labelled mannitol from serum into cerebrospinal fluid and brain. Exp Neurol 1964, 10:264-270.

84. Peterson B, Khanna S, Fisher B, Marshall L: Prolonged hypernatremia controls elevated intracranial pressure in head-injured pediatric patients. Crit Care Med 2000, 28:1136-1143.

85. Qureshi Al, Suarez Jl, Bhardwaj A, et al: Use of hypertonic (3\%) saline/ acetate infusion in the treatment of cerebral edema: effect on intracranial pressure and lateral displacement of the brain. Crit Care Med 1998, 26:440-446.

86. Kamel H, Navi BB, Nakagawa K, Hemphill JC, Ko NU: Hypertonic saline versus mannitol for the treatment of elevated intracranial pressure: a meta-analysis of randomized clinical trials. Crit Care Med 2011, 39(3):554-559.

87. Shiozaki T, Sugimoto $H$, Taneda M, et al: Effect of mild hypothermia on uncontrollable intracranial hypertension after severe head injury. J Neurosurg 1993, 79:363-368

88. Marion DW, Penrod LE, Kelsey SF, et al: Treatment of traumatic brain injury with moderate hypothermia. New Engl J Med 1997, 336:540-546.

89. Clifton GL, Miller ER, Choi SC, et al: Lack of effect of induction of hypothermia after acute brain injury. New Engl I Med 2001, 344:556-563.

90. Clifton GL, Valadka A, Zygun D, Coffey CS, Drever P, Fourwinds S, Janis LS, Wilde E, Taylor P, Harshman K, Conley A, Puccio A, Levin HS, McCauley SR, Bucholz RD, Smith KR, Schmidt JH, Scott JN, Yonas H, Okonkwo DO: Very early hypothermia induction in patients with severe brain injury (the National Acute Brain Injury Study: Hypothermia II): a randomised trial. Lancet Neurol 2011, 10:131-139.

91. Yablon SA: Post-traumatic seizures. Arch Phys Med Rehabil 1993, 74:983-1001.

92. Temkin NR: Risk factors for posttraumatic seizures in adults. Epilepsia 2003, 44(Suppl 10):18-20.

93. Kaufman HH, Satterwhite T, McConnell BJ, et al: Deep vein thrombosis and pulmonary embolism in head-injured patients. Angiology 1983, 34:627-638.

94. Norwood SH, McAuley CE, Berne JD, et al: Prospective evaluation of the safety of enoxaparin prophylaxis for venous thromboembolism in patients with intracranial hemorrhagic injuries. Arch Surg 2002, 137:696-70.

95. Devlin JW, Claire KS, Dulchavsky SA, Tyburski JG: Impact of trauma stress ulcer prophylaxis guidelines on drug cost andfrequency of major gastrointestinal bleeding. Pharmacotherapy 1999, 19:452-460.

96. Pharmacists ASoHs: ASHP Therapeutic Guidelines on Stress Ulcer Prophylaxis. ASHP Commission on Therapeutics and approved by the ASHP Board of Directors on November 14, 1998. Am J Health Syst Pharm 1999, 56:347-379.

97. Rapp RP, Young B, Twyman D, et al: The favorable effect of early parenteral feeding on survival in head-injured patients. J Neurosurg 1983, 58:906-912.

98. Heyland DK, Mac Donald S, Keefe L, et al: Total parenteral nutrition in critically ill patient: a meta-analysis. JAMA 1998, 280:2013-2019.

99. Krishnan JA, Parce PB, Martinez A, Diette GB, Brower RG: Caloric intake in medical ICU patients: consistency of care with guidelines and relationship to clinical outcomes. Chest 2003, 124(1):297-305.

100. Dickerson RN, Boschert KJ, Kudsk KA, Brown RO: Hypocaloric enteral tube feeding in critically ill obese patients. Nutrition 2002, 18(3):241-246.

101. Ibrahim EH, Mehringer L, Prentice D, Sherman G, Schaiff R, Fraser V, Kollef $\mathrm{MH}$ : Early versus late enteral feeding of mechanically ventilated patients: results of a clinical trial. JPEN J Parenter Enteral Nutr 2002, 26(3):174-181.

102. Stapleton RD, Jones N, Heyland DK: Feeding critically ill patients: what is the optimal amount of energy? Crit Care Med 2007, 35(9 Suppl):S535-540
103. Lam AM, Winn HR, Cullen BF, et al: Hyperglycemia and neurological outcome in patients with head injury. J Neurosurg 1991, 75:545-551.

104. Young B, Ott L, Dempsey R, et al: Relationship between admission hyperglycemia and neurologic outcome of severely brain-injured patients. Ann Surg 1989, 210:466-473.

105. Rovlias A, Kotsou S: The influence of hyperglycemia on neurological outcome in patients with severe head injury. Neurosurgery 2000, 46:335-342.

106. Cochran A, Scaife ER, Hansen KW, Downey EC: Hyperglycemia and outcomes from pediatric traumatic brain injury. J Trauma 2003, 55:1035-1038.

107. Jeremitsky E, Omert LA, Dunham CM, Wilberger J, Rodriguez A: The impact of hyperglycemia on patients with severe brain injury. J Trauma 2005, 58(1):47-50.

108. Salim A, Hadjizacharia P, Dubose J, Brown C, Inaba K, Chan LS, Margulies D: Persistent hyperglycemia in severe traumatic brain injury: an independent predictor of outcome. Am Surg 2009, 75:25-29.

109. Meier R, Béchir M, Ludwig S, Sommerfeld J, Keel M, Steiger P, Stocker R, Stover JF: Differential temporal profile of lowered blood glucose levels ( 3.5 to $6.5 \mathrm{mmol} / \mathrm{l}$ versus 5 to $8 \mathrm{mmol} / \mathrm{l}$ ) in patients with severe traumatic brain injury. Crit Care 2008, 12:R98.

110. Vespa P, Boonyaputthikul R, McArthur DL, Miller C, Etchepare M, Bergsneider M, Glenn T, Martin N, Hovda D: Intensive insulin therapy reduces microdialysis glucose values without altering glucose utilization or improving the lactate/pyruvate ratio after traumatic brain injury. Crit Care Med 2006, 34(3):850-856

111. Oddo M, Schmidt JM, Carrera E, Badjatia N, Connolly ES, Presciutti M, Ostapkovich ND, Levine JM, Le Roux P, Mayer SA: Impact of tight glycemic control on cerebral glucose metabolism after severe brain injury: a microdialysis study. Crit Care Med 2008, 36(12):3233-3238.

112. Zafar SN, lqbal A, Farez MF, Kamatkar S, de Moya MA: Intensive insulin therapy in brain injury: a meta-analysis. J Neurotrauma 2011, 28(7):1307-1317.

113. Marion DW: Optimum serum glucose levels for patients with severe traumatic brain injury. F 1000 Med Rep 2009, 1:42.

114. Roberts I, Yates D, Sandercock P, Farrell B, Wasserberg J, Lomas G, Cottingham R, Svoboda P, Brayley N, Mazairac G, Laloë V, Muñoz-Sánchez A, Arango M, Hartzenberg B, Khamis $H$, Yutthakasemsunt $S$, Komolafe E, Olldashi F, Yadav Y, Murillo-Cabezas F, Shakur H, Edwards P, CRASH trial collaborators: Effect of intravenous corticosteroids on death within 14 days in 10008 adults with clinically significant head injury (MRC CRASH trial): randomised placebo-controlled trial. Lancet 2004, 364:1321-1328.

115. Kassell NF, Hitchon PW, Gerk MK, Sokoll MD, Hill TR: Alterations in cerebral blood flow, oxygen metabolism, and electrical activity produced by high dose sodium thiopental. Neurosurgery 1980, 7:598-603.

116. Stover JF, Stocker R: Barbiturate coma may promote reversible bone marrow suppression in patients with severe isolated traumatic brain injury. Eur J Clin Pharmacol 1998, 54:529-534.

117. Clifton GL, Miller ER, Choi SC, Levin HS: Fluid thresholds and outcome from severe brain injury. Crit Care Med 2002, 30:739-745.

118. Finfer S, Bellomo R, Boyce N, French J, Myburgh J, Norton R: A comparison of albumin and saline for fluid resuscitation in the intensive care unit. $N$ Engl J Med 2004, 350:2247-2256.

119. Kerwin AJ, Schinco MA, Tepas JJ, Renfro WH, Vitarbo EA, Muehlberger M: The use of $23.4 \%$ hypertonic saline for the management of elevated intracranial pressure in patients with severe traumatic brain injury: a pilot study. J Trauma 2009, 67:277-282.

120. Froelich M, Ni Q, Wess C, Ougorets I, Härtl R: Continuous hypertonic saline therapy and the occurrence of complications in neurocritically ill patients. Crit Care Med 2009, 37(4):1433-1441.

121. Harrigan MR: Cerebral salt wasting. Crit Care Clin 2001, 17:125-138.

122. Helms O, Freys G, Pottecher T: Severe hypophosphatemia and grave head injury. Ann Fr Anesth Reanim 2002, 21:525-529.

123. Polderman KH, Bloemers FW, Peerdeman SM, et al: Hypomagnesemia and hypophosphatemia at admission in patients with severe head injury. Crit Care Med 2000, 28:2022-2025.

124. Eker C, Asgeirsson B, Grände PO, Schalén W, Nordström CH: Improved outcome after severe head injury with a new therapy based principles for brain volume regulation and improved microcirculation. Critical Care Medicine 1998, 26:1881-1886. 
125. Ng I, Lim J, Wong HB: Effects of head posture on cerebral hemodynamics: its influences on intracranial pressure, cerebral perfusion pressure, and cerebral oxygenation. Neurosurgery 2004, 54(3):593-597, discussion 598.

126. Ledwith MB, Bloom S, Maloney-Wilensky E, Coyle B, Polomano RC, Le Roux PD: Effect of body position on cerebral oxygenation and physiologic parameters in patients with acute neurological conditions. $J$ Neurosci Nurs 2010, 42(5):280-287.

127. Tablan OC, Anderson LJ, Besser R, Bridges C, Hajjeh R: CDC; Healthcare Infection Control Practices Advisory Committee. Guidelines for preventing health care-associated pneumonia 2003: recommendations of CDC and the Healthcare Infection Control Practices Advisory Committee. MMWR Recomm Rep 2004, 53(RR-3):1-36.

128. O'Grady NP, Alexander M, Burns LA, Dellinger EP, Garland J, Heard SO, Maki $D G$, et al: Guidelines for the prevention of intravascular catheterrelated infections, 2011. Clin Infect Dis 2011, 52:1087-1099.

129. Albanèse J, Leone M, Alliez JR, Kaya JM, Antonini F, Alliez B, Martin C: Decompressive craniectomy for severe traumatic brain injury: Evaluation of the effects at one year. Crit Care Med 2003, 31(10):2535-2538.

130. Cooper J, Rosenfeld J, Murray L, Arabi Y, Davies A, D'Urso P, Kossmann T, Ponsford J, Seppelt I, Reilly P, Wolfe R, for the DECRA Trial Investigators and the Australian and New Zealand Intensive Care Society Clinical Trials Group: Decompressive Craniectomy in Diffuse Traumatic Brain Injury. N Engl J Med 2011, 364:1493-1502.

131. Hukkelhoven CW, Steyerberg EW, Habbema JD, Farace E, Marmarou A, Murray GD, Marshall LF, Maas Al: Predicting outcome after traumatic brain injury: development and validation of a prognostic score based on admission characteristics. J Neurotrauma 2005, 22(10):1025-1039.

132. Tasaki O, Shiozaki T, Hamasaki T, Kajino K, Nakae H, Tanaka H, Shimazu T, Sugimoto H: Prognostic indicators and outcome prediction model for severe traumatic brain injury. J Trauma 2009, 66(2):304-308.

doi:10.1186/1757-7241-20-12

Cite this article as: Haddad and Arabi: Critical care management of severe traumatic brain injury in adults. Scandinavian Journal of Trauma, Resuscitation and

Emergency Medicine 2012 20:12.

\section{Submit your next manuscript to BioMed Central and take full advantage of:}

- Convenient online submission

- Thorough peer review

- No space constraints or color figure charges

- Immediate publication on acceptance

- Inclusion in PubMed, CAS, Scopus and Google Scholar

- Research which is freely available for redistribution

Submit your manuscript at www.biomedcentral.com/submit 